\title{
In vitro growth and carbon utilization of the green-leaved orchid Dendrobium officinale are promoted by mycorrhizal associations
}

\author{
Qiu-Xia Wang ${ }^{1,2}$, Ning Yan ${ }^{1}$, Da-Gan $\mathrm{Ji}^{1}$, Shu-Yun $\mathrm{Li}^{1}$ and Hong Hu${ }^{1 *}$
}

\begin{abstract}
Background: Mycorrhizal associations play a key role in the life cycle and evolutionary history of orchids. All orchids grow from extremely small seeds that are lacking in reserves, and germination and growth into an underground heterotrophic, achlorophyllous stage depend upon symbiotic fungi to provide nutrient. However, the nutritional physiology between this symbiosis and green-leaved orchids is still unclear. To understand further how these associations affect growth and carbon utilization of green orchids, the green orchids were inoculated with two symbiotic fungi isolated from the roots of a wild orchid (Dendrobium officinale) in vitro and ${ }^{13} \mathrm{C}$ stable isotope signature experiments were designed to analyze carbon nutrition acquisition.

Results: After two months, both fungi had formed mycorrhizal associations with the host roots. Moreover, the growth rate was more rapid for the mycorrhizal seedlings than for the non-mycorrhizal seedlings. The mycorrhizal seedlings not only absorbed more ${ }^{13} \mathrm{C}$ from the substrate, but also the S3-mycorrhizal seedlings assimilated more atmospheric ${ }^{13} \mathrm{CO}_{2}$ due to significantly higher effective quantum yield of photosystem II, compared with the nonmycorrhizal seedlings. These results suggested that the green orchids could receive more $C$ nutrition from the substrate due to symbiotic fungi, and photosynthesis capacity of the green $D$. officinale could be enhanced by the S3 fungus, therefore carbon nutrition acquisition also increased. As a result, the S1- and S3- mycorrhizal seedlings showed markedly higher biomass and polysaccharides contents than the non-mycorrhizal seedlings.
\end{abstract}

Conclusions: These results improve our understanding of the mycorrhizal functioning in the green Dendrobium and show some potential application in the cultivation of D. officinale.

Keywords: ${ }^{13} \mathrm{C}$; Dendrobium officinale; Growth; Mycorrhizal associations; Polysaccharides

\section{Background}

Mycorrhizal associations have an essential role in the life cycle and evolutionary history of orchids (Rasmussen and Rasmussen 2009). A division of orchids into three physiological types (fully autotrophic, fully mycoheterotrophic $(\mathrm{MH})$, partial $\mathrm{MH}$ or mixotrophs) is based on carbon nutrition (Dearnaley et al. 2012). Regardless of their carbon at adult stage, all orchids grow from extremely small seeds that are lacking in reserves, and germination and growth into an underground heterotrophic, achlorophyllous stage (protocorm stage) depend upon symbiotic fungi to provide carbon nutrient (Smith

\footnotetext{
* Correspondence: huhong@mail.kib.ac.cn

${ }^{1}$ Key Laboratory of Economic Plants and Biotechnology, Kunming Institute of Botany, Chinese Academy of Sciences, Kunming 650201, China Full list of author information is available at the end of the article
}

and Read 1997; Arditti and Ghani 2000; Johnson et al. 2007). For adult photosynthetic stage, carbohydrates are also essential for orchid growth (Wang et al., 2008). Moreover, adult orchid roots are consistently heavily colonized by mycorrhizal fungi (McCormick et al. 2006). However, for adult orchids, it is still a matter of discussion whether and to what extent such carbohydrates are actually influenced by their symbiotic fungi. Therefore, accurate measurements of $\mathrm{C}$-source uptake by mycorrhizal and non-mycorrhizal orchids are a critical component to better understanding of mycorrhizal functioning (Cameron et al. 2008).

Stable isotope signatures have proven that some fully autotrophic terrestrial orchids can acquire carbon, nitrogen, phosphate via the "up-flow" pathway through their symbiotic fungi (Cameron et al. 2006, 2007, 2008; 
Hynson et al. 2012). Standard experiments with those signatures have been conducted with media containing labeled substrates. $\mathrm{C}, \mathrm{N}$ and $\mathrm{P}$ sources can be supplied through the media, but also carbon can also be obtained through atmospheric $\mathrm{CO}_{2}$. The conventional view is that plants can receive $\mathrm{C}$ from photosynthate by fixing $\mathrm{CO}_{2}$ and the photosynthate can also affect the growth and development in a plant. However, whether the ability of $\mathrm{CO}_{2}$ assimilation for green orchids is influenced by its fungal partner still needs experimental confirmation.

A 'multifunctional' perspective of mycorrhizal symbiosis accounts for the ways in which such fungi influence carbon-partitioning within plants (Finlay 2004). The concept of carbon nutrition has relied, to a large degree, on studies of carbonhydrates, which, in many cases, are used as a synonym for $\mathrm{C}$ accumulation (Mengel and Kirkby 2001). Carbon that is fixed from the atmosphere takes the form of sugars that are, on average, slightly enriched in ${ }^{13} \mathrm{C}$ compared with secondary metabolites and structural $C$ (Hynson et al. 2012). Polysaccharides play a vital role in plant metabolism and growth. (Chang and Chou 2007) have reported that mycorrhizae markedly enhance the amount of polysaccharides produced in Anoectochilus formosanus. However, the mechanism by which this is accomplished remains unclear. Based on this knowledge, it can be hypothesized that 1) the photosynthetic capacity in green-leaved orchid would improve by their mycorrhizal fungi, and 2) carbon acquisition, soluble polysaccharides accumulation and biomass production would increase in mycorrhizal seedlings.

Here, we provided ${ }^{13} \mathrm{CO}_{2}$ and ${ }^{13} \mathrm{C}$-glucose in a quantitative investigation of $\mathrm{C}$-source uptake by both mycorrhizal and non-mycorrhizal orchid plants and determined chlorophyll fluorescence of mycorrhizal and non-mycorrhizal orchid leaves. Dendrobium is one of the largest genera in Orchidaceae (Mohanty et al. 2012). Being rich in polysaccharides, $D$. officinale is a valuable Chinese traditional medicine that has immunological activity and can inhibit the growth of tumor cells (Luo et al. 2000; Lin et al. 2011). Therefore, positive results from our experiments would be beneficial for its commercial production.

\section{Methods \\ Plant material \\ Adult plants}

Wild plants of Dendrobium officinale were collected from a subtropical forest at Xishuangbanna $\left(21.7^{\circ} \mathrm{N}\right.$, 100.8 ${ }^{\circ}$ ), Yunnan Province, China.

\section{Seedlings}

Ripe capsules of $D$. officinale, collected from a nursery in Puer $\left(22.78^{\circ} \mathrm{N}, 100.97^{\circ} \mathrm{E}\right)$, Yunnan Province, China, were washed under tap water and surface-sterilized with $75 \%$ ethanol. They were soaked in a $0.1 \% \mathrm{HgCl}_{2}$ solution for $10 \mathrm{~min}$ and then rinsed with sterile distilled water three times. Afterward, they were blotted with sterile filter paper and split. The seeds were sown into culture bottles (8-cm diam) containing $100 \mathrm{~mL}$ of a Harvais medium (Harvais 1982) (autoclaved beforehand at $121^{\circ} \mathrm{C}$ for $30 \mathrm{~min})$ and incubated in the tissue culture room $(12 \mathrm{~h}$ of daylight, $50 \mu \mathrm{mol} \mathrm{m} \mathrm{m}^{-2} \mathrm{~s}^{-1}, 26 \pm 1^{\circ} \mathrm{C}$ ). Germinated seedlings with roots were aseptically transplanted into fresh culture bottles with Harvais medium.

\section{Isolation of endophytic fungi}

Healthy roots from wild plants of $D$. officinale were selected, rinsed under tap water, and washed again in sterile distilled water. Once segmented, they were surface-sterilized by consecutive immersions for 8 to $10 \mathrm{~min}$ in $0.1 \% \mathrm{HgCl}_{2}$, and then rinsed five times with sterile distilled water. After surface-drying, the root segments were aseptically cut into approximately 0.5 - to 1-cm sections, and transferred to 9-cm Petri dishes containing potato dextrose agar (PDA: $20 \%$ potato, $2 \%$ glucose, and $1.5 \%$ agar). The dishes were incubated in the dark at $25^{\circ} \mathrm{C}$ until fungal hyphae emerged from inside the roots. Pure cultures were obtained by transferring the hyphae onto fresh PDA and storing them in PDA slant tubes at $4^{\circ} \mathrm{C}$. In all of these isolates, two fungi (named S1 and S3) were found to stimulate the growth of tissue-cultured seedlings of $D$. officinale through artificial inoculation, so they were selected for further study.

\section{Molecular identification of fungi}

Isolates S1 and S3 were cultured on PDA media. Because other reproductive structures failed to sporulate on that media, we subjected S1 and S3 to molecular analysis of the internal transcribed region (ITS) of the 5.8SrDNA and the large subunit gene of mitochondrial rDNA (mtLSU) sequences, respectively, using universal fungal primer combinations ITS1/ITS4 (Ma et al. 2003) and ML5/ML6 (Bruns et al. 1998). DNA was extracted from 30-day-old PDA-cultured colonies according to the cetyltrimethyl ammonium bromide (CTAB) method (Doyle and Doyle 1987). PCR reactions (25 $\mu \mathrm{L})$ were performed using $2.5 \mu \mathrm{L}$ of $10 \times$ buffer (with $\mathrm{Mg}^{2+}$ ), $2 \mu \mathrm{L}$ of $2.5 \mathrm{mM}$ dNTP, $0.5 \mu \mathrm{L}$ of TaqE (2.5U), $2 \mu \mathrm{L}$ of $5 \mu \mathrm{M}$ of each primer, $2 \mu \mathrm{L}$ of undiluted DNA template and $14 \mu \mathrm{L}$ of $\mathrm{ddH}_{2} \mathrm{O}$. The cycle parameters included denaturation at $95^{\circ} \mathrm{C}$ for $3 \mathrm{~min}$; then 35 cycles of denaturation at $94^{\circ} \mathrm{C}$ for $1 \mathrm{~min}$, annealing at $53^{\circ} \mathrm{C}$ for $50 \mathrm{~s}$, and elongation at $72^{\circ} \mathrm{C}$ for $1 \mathrm{~min}$; followed by a final extension at $72^{\circ} \mathrm{C}$ for $7 \mathrm{~min}$. The PCR products were purified and directly sequenced in an ABI Prism 3730 Sequencer (Applied Biosystems, Foster City, CA, USA) at the Shanghai Sangon Biological Engineering Technology \& 
Services Co. Ltd. The sequences were aligned by Contig Express and adjusted manually.

\section{Inocula of fungi}

Samples of the S1 and S3 fungi were transferred to 9-cm Petri dishes containing PDA media for incubation in the dark at $25^{\circ} \mathrm{C}$ for three weeks, respectively.

\section{Inoculation experiments}

Before experimental analysis, the two-month-old seedlings of $D$. officinale were trimmed to provide uniformly sized materials, each consisting of a stem supporting three to five leaves and two to three roots of $20 \mathrm{~mm}$ in length. Eight uniform seedlings were implanted into one culture bottle containing $100 \mathrm{~mL}$ of $1 / 2 \mathrm{MS}$ (halfstrength concentrations of the major and minor salts of the MS medium) (Murashige and Skoog 1962) medium supplemented with $0.75 \%$ sucrose and $0.75 \%$ agar after weighed (Hou and Guo 2009). For the inoculation treatments, a single mycelia plug (6-mm diam), cut from the margin of a fungal colony (either S1 or S3), was placed into the middle of each bottle. The control involved eight similarly placed seedlings that were not inoculated with any fungi. Each treatment comprised 25 replicates. All treatments were kept in the tissue culture room for two months.

\section{Visualization of fungal infection in roots}

The fungal hyphae were stained with a chitin-specific dye, wheat germ agglutinin-alexa fluor (WGA-AF) 488 conjugate (Molecular Probes, Karlsruhe, Germany). Fungal infection was observed through a previously described technique (Doehlemann et al. 2008) with some modifications. After inoculation period, the root segments were incubated in the staining solution $10 \mu \mathrm{g} / \mathrm{ml}$ WGA-AF 488; $0.02 \%$ Tween 20 in $1 \times$ PBS (137 mM $\mathrm{NaCl}, 27 \mathrm{mM} \mathrm{KCl}, 100 \mathrm{mM} \mathrm{Na} \mathrm{HPO}_{4}, 2 \mathrm{mM} \mathrm{K}_{2} \mathrm{HPO}_{4}$, adjusted to $\mathrm{pH} \mathrm{7.4)} \mathrm{for} 60 \mathrm{~min}$; during this period, the solution was vacuum infiltrated three times ( 3 min each) at $25 \mathrm{~mm}$ of $\mathrm{Hg}$. After the samples were rinsed in $1 \times$ PBS (phosphate buffer saline) ( $\mathrm{pH}$ 7.4) three times, they were transferred into a Propidium Iodide (PI, Sigma) solution $\left(20 \mu \mathrm{g} \mathrm{mL}^{-1} \mathrm{PI}\right.$ in $\left.1 \times \mathrm{PBS}\right)$ for $3 \mathrm{~min}$ and then rinsed in $1 \times \mathrm{PBS}$ ( $\mathrm{pH}$ 7.4) three times. Finally, the samples were mounted on glass slides.

Confocal images were recorded on a laser scanning confocal microscope (OLYMPUS FV1000). The WGAAF 488 was excited with a $488 \mathrm{~nm}$ laser and detected at 500 to $540 \mathrm{~nm}$. The PI was excited with a $559 \mathrm{~nm}$ laser and detected at 580 to $619 \mathrm{~nm}$.

\section{Light microscopy examination}

Twenty root segments were fixed in anhydrous ethanol for above $24 \mathrm{~h}$, and then freehand sections were observed and photographed on a light microscope equipped with a camera (Leica DM 2500, Germany).

\section{Chlorophyll fluorescence measurements}

We conducted measurement for the light response of chlorophyll fluorescence in leaves from in vitro grown seedlings at $25^{\circ} \mathrm{C}$ with IMAGING-PAM (Heinz Walz, Effeltrich, Germany) connected to a computer with control software. Six mature leaves from eight seedlings of each treatment were light-adapted $(55 \mu \mathrm{mol}$ photons $\mathrm{m}^{-2} \mathrm{~s}^{-1}$ ) for $15 \mathrm{~min}$ at $25^{\circ} \mathrm{C}$ before the measurement of light response curves. The effective quantum yield of PSII $\left(\Phi_{\text {PSII }}\right)$ is calculated as: $\Phi_{\text {PSII }}=\left(F_{m}{ }^{\prime}-F_{s}\right) / F_{m}{ }^{\prime}$ (Genty et al. 1989), where $F_{m}$ ' is the maximum fluorescence values upon illumination of a pulse $(800 \mathrm{~ms})$ of saturating light $\left(10,000 \mu \mathrm{mol}\right.$ photons $\left.\mathrm{m}^{-2} \mathrm{~s}^{-1}\right)$ in the lightadapted state, and $F_{s}$ is steady-state fluorescence in light.

\section{Experimental design for ${ }^{13} \mathrm{C}$ stable isotope signature in a microcosm}

Each of our experimental microcosms consisted of a culture bottle with a round, sealed septum (8-mm diam) passed through the middle of the lid (Figure 1). To supply ${ }^{13} \mathrm{CO}_{2}$, each microcosm contained a $1.5-\mathrm{mL}$ microtube with $30 \mathrm{mg}$ of sterile ${ }^{13} \mathrm{C}$-labelled barium

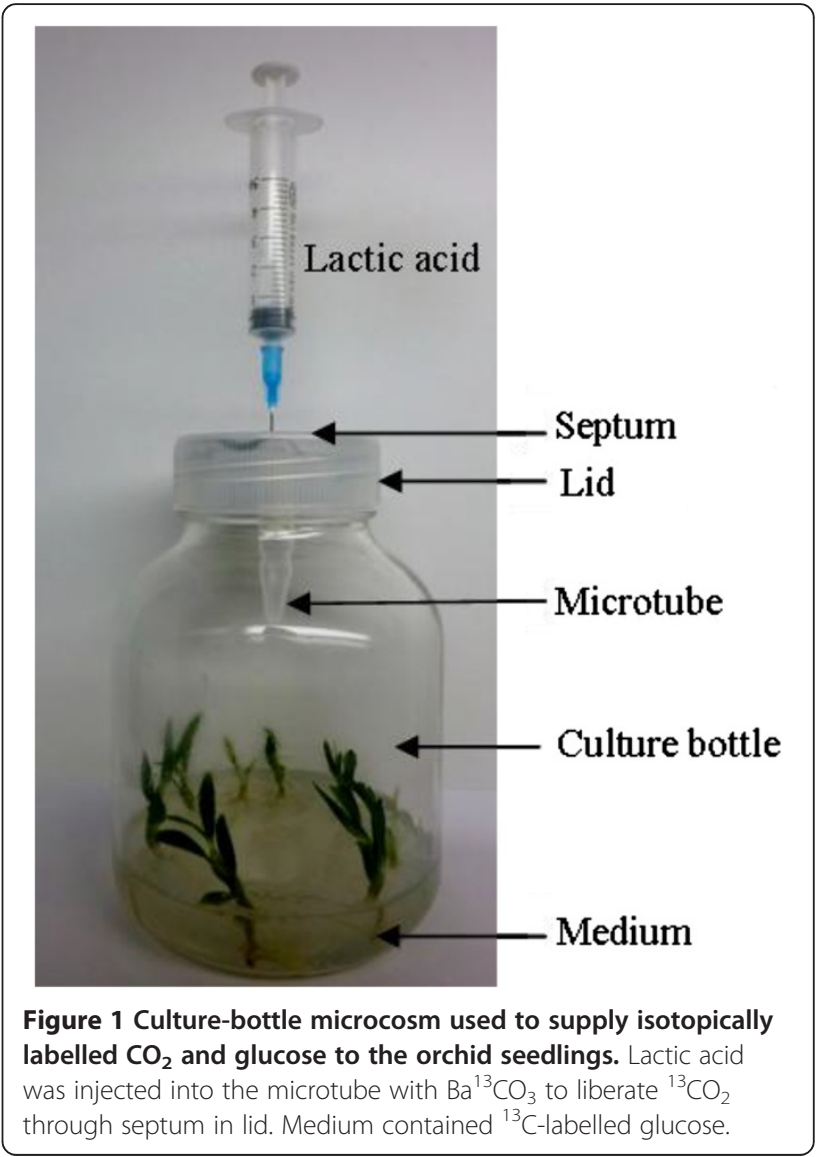


carbonate, plus $100 \mathrm{~mL}$ of $1 / 2$ MS medium supplemented with $100 \mathrm{mg}$ of unlabelled glucose and $0.75 \%$ agar. To determine $\mathrm{C}$ absorbed from substrates by plants, each microcosm had a $1.5-\mathrm{mL}$ microtube with $30 \mathrm{mg}$ sterile unlabelled barium carbonate and $100 \mathrm{~mL}$ of $1 / 2$ MS medium supplemented with $100 \mathrm{mg}$ of ${ }^{13} \mathrm{C}$-labelled glucose and $0.75 \%$ agar. Before the experiments began, the seedlings were trimmed to provide uniformly sized materials, each having three to five leaves and two to three roots. Three treatments per labeling experiment were established, with each treatment prepared as described for our inoculation experiments. However, a mycelia plug was placed near the roots of each seedling, rather than in the middle of medium, so that fungal infection would occur as soon as possible. Replicate treatments $(n=6)$ were preformed in case of contamination. All treatments were placed into the tissue culture room (12 $\mathrm{h}$ of daylight, $50 \mu \mathrm{mol} \mathrm{m} \mathrm{m}^{-2} \mathrm{~s}^{-1}, 26 \pm 1^{\circ} \mathrm{C}$ ). To liberate the ${ }^{13} \mathrm{CO}_{2}$ and unlabelled $\mathrm{CO}_{2}$ from the ${ }^{13} \mathrm{C}$-labelled and unlabelled barium carbonate, respectively, we injected $0.2 \mathrm{~mL}$ of a $25 \%$ (v: v) sterile lactic acid solution injected through the sealed septum in the middle of each lid. Afterward, the microcosms were sealed until the end of the experimental period.

\section{Analysis of ${ }^{13} \mathrm{C}$ stable isotope abundance}

After two months, the plants were harvested from each bottle and dried at $80^{\circ} \mathrm{C}$ for $48 \mathrm{~h}$. They were then ground to a fine powder to obtain a representative subsample of plant tissue for further analysis. Relative $\mathrm{C}$ isotope abundances were measured by isotope ratio mass spectrometer (Delta V Advantage, USA) at Institute of Desertification Studies, China Academy of Forestry, as described by (Liebel and Gebauer 2011). Three test substances of varying sample weight were routinely analyzed within each treatment. The maximum variation in $\delta^{13} \mathrm{C}$ was always below $0.1 \%$.

\section{Determination of polysaccharides contents}

Dry samples from the aboveground parts of each treatment were homogenized, and their percentages of polysaccharides were determined by the phenol-sulphuric acid method (Pharmacopoeia Committee of the P.R. China 2010). Each treatment was performed in triplicates to minimize errors.

\section{Data collection and statistical analysis}

Two months after inoculation, the plants were harvested to record their heights, stem lengths, stem diameters, internode lengths and numbers of nodes. For each culture bottle, the fresh and dry weights, and the numbers of new roots and tillers also were determined. The eight plants from each bottle were weighed and then dried for $48 \mathrm{~h}$ at $80^{\circ} \mathrm{C}$ before measuring dry weight. The increment in fresh weight per bottle was calculated as plants weight after inoculation minus plant weight before inoculation. The statistical package SPSS 17.0 for Windows was used for data analysis. Differences among the treatments and control groups were tested with a one-way analysis of variance (ANOVA), followed by tests for least significant difference test. Values were presented as means \pm standard error (SE).

\section{Results}

\section{Formation of mycorrhizal associations}

After two months of inoculation, S1 and S3 hyphae had spread over the root surfaces, invaded the cortical cells, and colonized the intracellular spaces of the roots of the inoculated seedlings (Figure 2A, B, E). In the cortical region, the hyphae penetrated through the cell walls and entered next to the cortical cells (Figure 2C). No fungal hyphae or pelotons were observed within the root cells from the control (non-inoculated) seedlings (Figure 2D, F).

\section{Growth responses of $D$. officinale}

Two months after being inoculated with S1 or S3, the host plants showed enhanced growth (Table 1). Compared with the control seedlings, increments of fresh weight, dry weight, plant heights, stem lengths and diameters, internode lengths, and number of nodes, tillers and new roots were significantly higher in the mycorrhizal seedlings.

The mycorrhizal fungi were re-isolated from the D. officinale roots after two months of inoculation. As expected, no fungus was isolated from the noninoculated orchids. We then sequenced the ITS-5.8S rDNA sequences of the re-isolated fungus from the roots inoculated with $S 1$ as well as the mtLSU sequences of the re-isolated fungus from the S3-inoculated roots and verified that these fungi were the same as those used for the first inoculations (data unpublished).

\section{Chlorophyll fluorescence}

Values for ФPSII in the S3-mycorrhizal seedlings were significantly higher than those in the S1-mycorrhizal and non-mycorrhizal seedlings. However, values for ФPSII did not differ between the S1- mycorrhizal and nonmycorrhizal seedlings (Figure 3 ).

\section{Carbon utilization by different treatments} Both ${ }^{13} \mathrm{C}$ derived from ${ }^{13} \mathrm{CO}_{2}$ and ${ }^{13} \mathrm{C}$ from ${ }^{13} \mathrm{C}$-labelled glucose were readily detectable in the mycorrhizal and non-mycorrhizal seedlings (Figure 4). For the seedlings fed with only ${ }^{13} \mathrm{CO}_{2}$, the $\delta^{13} \mathrm{C}$ value in the $\mathrm{S} 3$ mycorrhizal seedlings was about 1.94-fold higher than that in the non-mycorrhizal seedlings, and was also significantly different from that calculated for the S1mycorrhizal seedlings. However, value for $\delta^{13} \mathrm{C}$ derived 

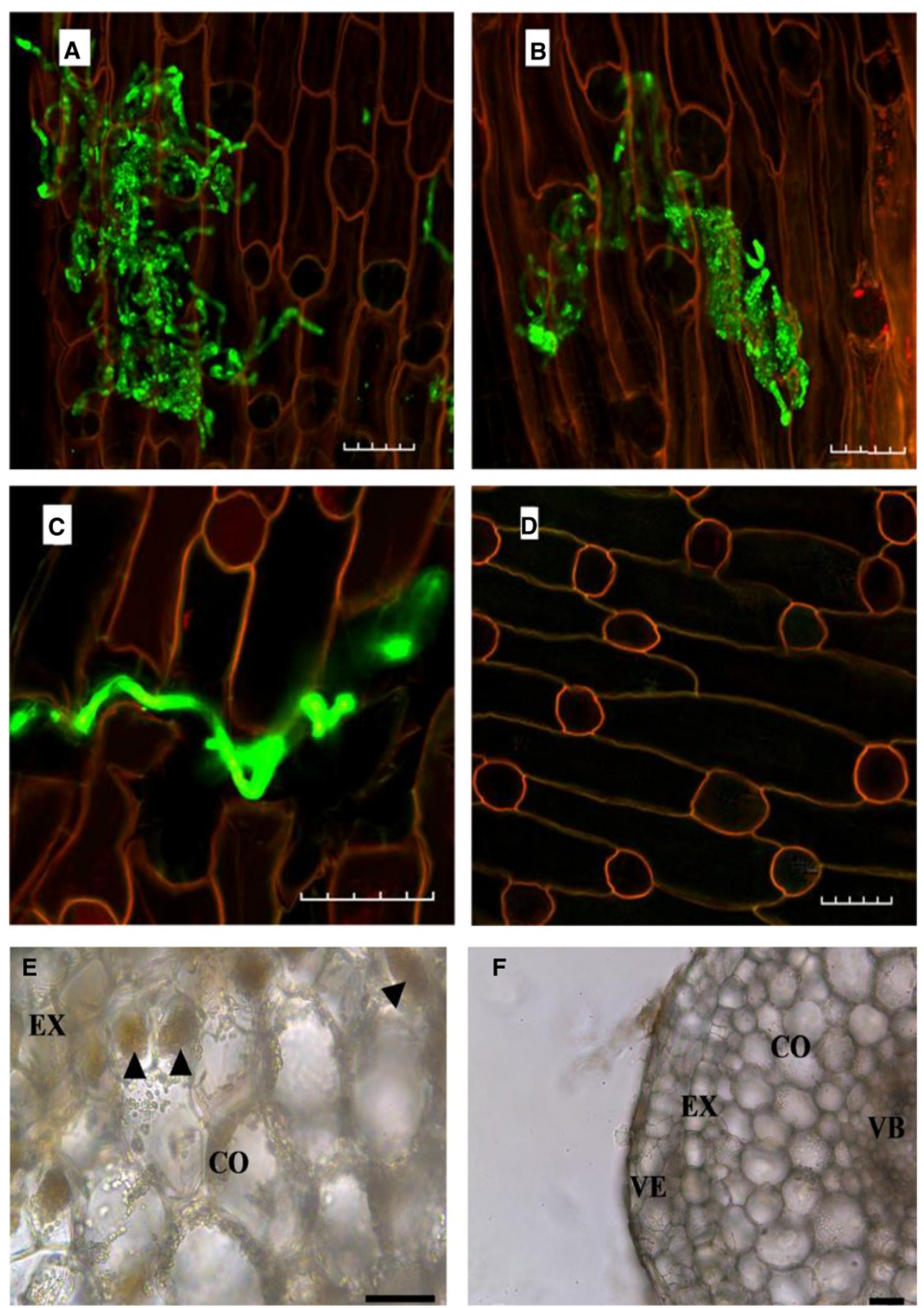

Figure 2 Mycorrhizal associations of Dendrobium officinale roots. A: Hyphae (green) from S1 fungus colonizing root cortical cells; B: Hyphae (green) of S3 fungus colonizing root cortical cells; C: Hyphae (green) penetrating cell wall and invading a neighbor cell in the root; D: Root cortical cells from non-inoculated control seedlings; $\mathbf{E}$ : Transverse section showing pelotons formed in the cortical cells of the inoculated roots; F: Transverse section of the control root. arrows, peloton; VE, velamen; EX, exodermis; CO, cortex; VB, vascular bundle Scale bar $=50 \mu \mathrm{m}$.

from ${ }^{13} \mathrm{CO}_{2}$ had no significant difference between the S1-mycorrhizal and non-mycorrhizal seedlings (Figure 4A). By contrast, $\delta^{13} \mathrm{C}$ derived from ${ }^{13} \mathrm{C}$-glucose in the $\mathrm{S} 1$ - and S3-mycorrhizal seedlings was about 3.67- and 4.34- fold higher, respectively, than that in the control seedlings. Again, however, the $\delta^{13} \mathrm{C}$ value derived from ${ }^{13} \mathrm{C}$-glucose had no significant difference between the S1 and S3 treatments (Figure 4B).

\section{Polysaccharides contents}

Compared with the non-mycorrhizal seedlings, the mycorrhizal seedlings had significantly higher polysaccharides 
Table 1 Effects of S1 and S3 on the growth of Dendrobium officinale seedlings ( $n=25$ each)

\begin{tabular}{cccc}
\hline Parameters & S1 & S3 & Control \\
\hline Increment in fresh weight $(\mathrm{g})$ & $0.96 \pm 0.06 \mathrm{~b}$ & $1.27 \pm 0.05 \mathrm{c}$ & $0.57 \pm 0.02 \mathrm{a}$ \\
Dry weight $(\mathrm{g})$ & $0.06 \pm 0.00 \mathrm{~b}$ & $0.09 \pm 0.00 \mathrm{c}$ & $0.03 \pm 0.00 \mathrm{a}$ \\
Plant height $(\mathrm{cm})$ & $2.16 \pm 0.04 \mathrm{~b}$ & $2.12 \pm 0.06 \mathrm{~b}$ & $1.81 \pm 0.07 \mathrm{a}$ \\
Stem length $(\mathrm{cm})$ & $1.01 \pm 0.02 \mathrm{~b}$ & $1.14 \pm 0.04 \mathrm{c}$ & $0.89 \pm 0.03 \mathrm{a}$ \\
Stem diameter $(\mathrm{cm})$ & $0.18 \pm 0.01 \mathrm{~b}$ & $0.28 \pm 0.01 \mathrm{c}$ & $0.15 \pm 0.01 \mathrm{a}$ \\
Number of nodes & $3.09 \pm 0.06 \mathrm{~b}$ & $3.22 \pm 0.11 \mathrm{~b}$ & $2.72 \pm 0.01 \mathrm{a}$ \\
Internode length $(\mathrm{cm})$ & $0.31 \pm 0.01 \mathrm{~b}$ & $0.33 \pm 0.01 \mathrm{~b}$ & $0.25 \pm 0.01 \mathrm{a}$ \\
Number of tillers & $26.24 \pm 0.99 \mathrm{c}$ & $19.40 \pm 0.75 \mathrm{~b}$ & $7.24 \pm 0.60 \mathrm{a}$ \\
Number of new roots & $21.80 \pm 1.45 \mathrm{c}$ & $15.00 \pm 1.00 \mathrm{~b}$ & $9.68 \pm 0.68 \mathrm{a}$ \\
\hline
\end{tabular}

Different letters within the same row indicate that values (mean \pm standard error) are significantly different among treatments at $P<0.05$, based on LSD test. Control, non-inoculated seedlings.

percentages when harvested. Contents in the seedlings treated with S1 and S3 fungi were 1.42- and 1.46- fold, respectively, of those measured from the control. However, the two inoculation treatments did not differ significantly in their polysaccharide accumulations (Figure 5).

\section{Discussion}

The functioning of mycorrhizae depends upon the development of an association between a fungus and a host plant (Johnson et al. 1997). We demonstrated here that two isolates formed mycorrhizal associations with Dendrobium officinale. Both S1 and S3 markedly enhanced the growth of $D$. officinale seedlings. Although it has previously been documented that symbiotic fungi can

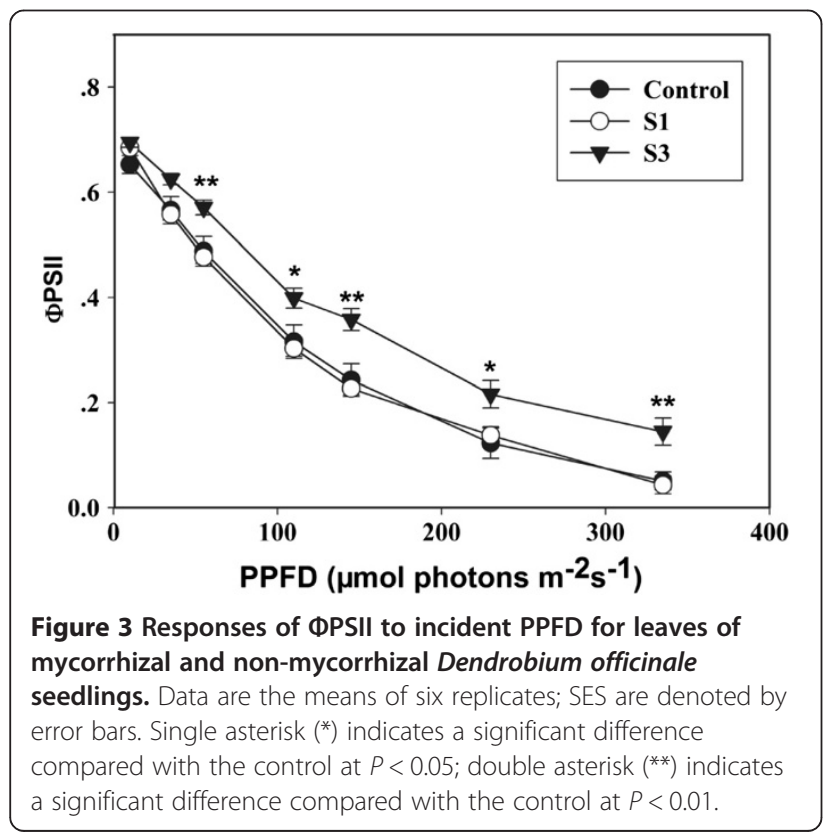

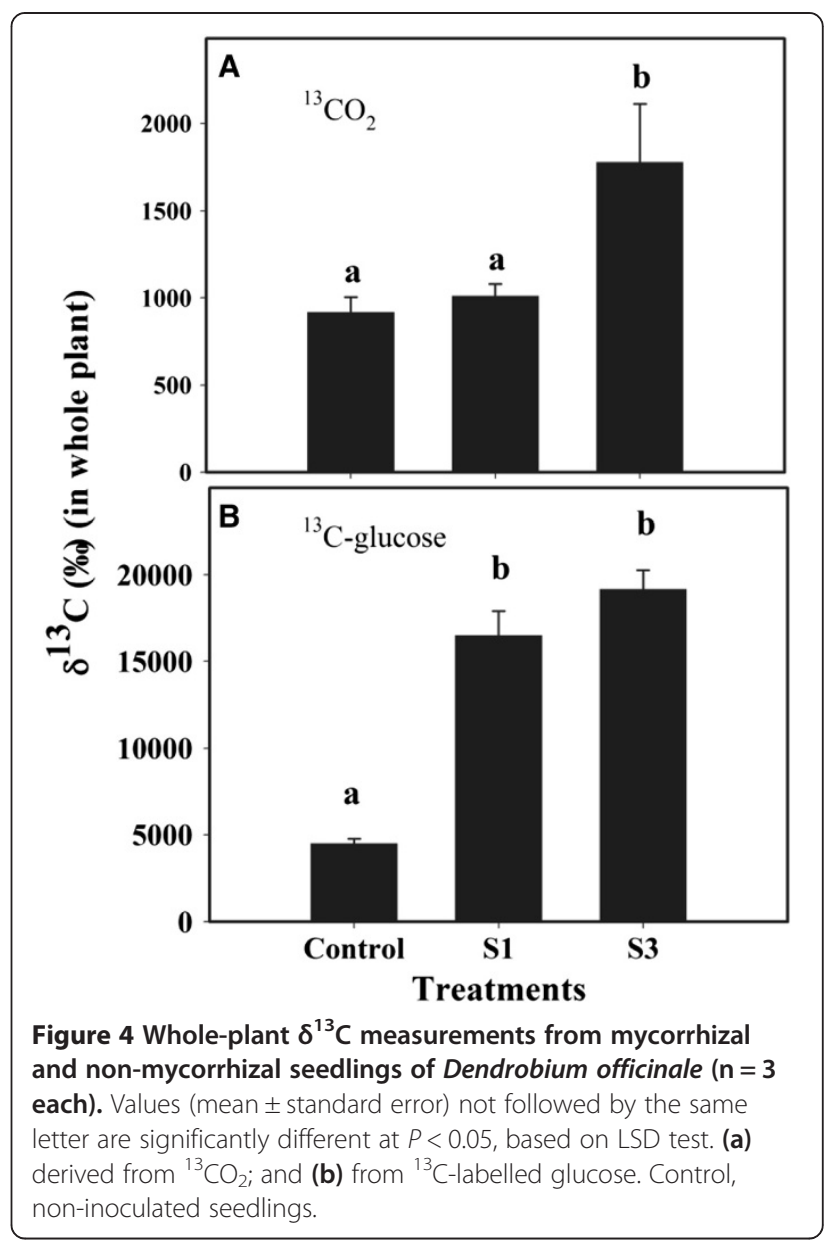

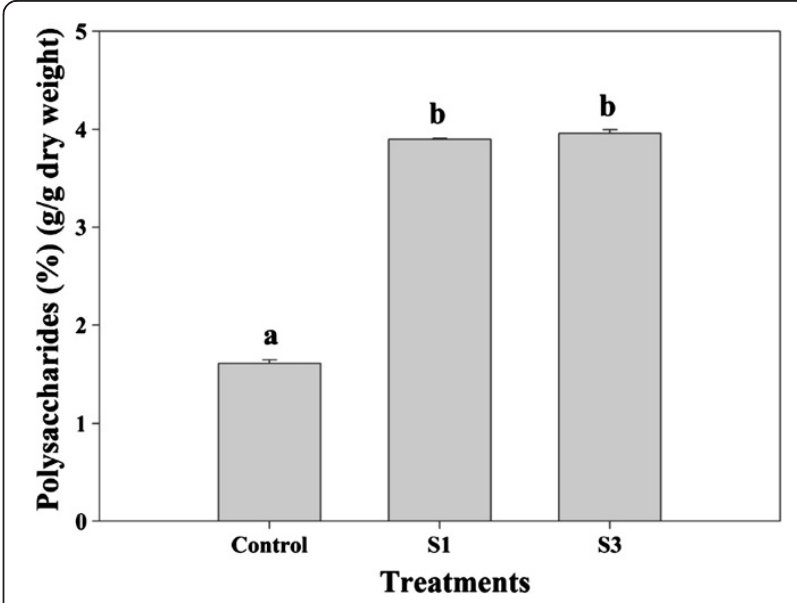

Figure 5 Effects of S1 and S3 on polysaccharides contents in Dendrobium officinale seedlings ( $\mathrm{n}=3$ each). Values (mean \pm standard error) not followed by the same letter are significantly different at $P<0.05$, based on LSD test. Control,

non-inoculated seedlings. 
promote the growth of their host plants (Stewart and Kane 2007; Zhang et al. 2012), the mechanism by which this occurs remains unclear.

Few previous studies have quantified the amount of $\mathrm{CO}_{2}$ that is assimilated in mycorrhizal versus non-mycorrhizal plants. Our study suggested that the amount of $\mathrm{CO}_{2}$ that is assimilated in the S3-mycorrhizal seedlings was significantly higher than that in the nonmycorrhizal seedlings. Some evidences have been reported that mycorrhizal seedlings have higher stomatal conductance and chlorophyll concentrations than nonmycorrhizal seedlings (Sheng et al. 2008; Zhou et al. 2009). This implies that the mycorrhizal seedlings have greater photosynthetic capacity. Another explanation for this phenomenon might be that a fungus can serve as a nutrient sink, because some orchid plantlets can transfer a substantial amount of photosynthate to its symbiotic fungi (Cameron et al. 2006). Other explanations might be that mycorrhizae can decrease the resistance (stomatal and mesophyll) to $\mathrm{CO}_{2}$ diffusion, or increase the activities of carboxylating enzymes, or change hormones levels in mycorrhizal plant (Reid et al. 1983). In the present study, to study photosynthesis we used chlorophyll fluorescence analysis, which has become one of the most powerful and relatively straightforward techniques. The results pointed out that ФPSII in the leaves of the S3-mycorrhizal seedlings was significantly higher than that in the S1-mycorrhizal and non-mycorrhizal seedlings. This implied that the capacity of photosynthetic electron flow of the S3-mycorrhizal seedlings was higher than that of the S1-mycorrhizal and non-mycorrhizal seedlings. Because there is a positive correlation between photosynthetic electron flow and $\mathrm{CO}_{2}$ assimilation, the amount of photosynthetic $\mathrm{CO}_{2}$ assimilation in the S3mycorrhizal seedlings was higher than that in the S1mycorrhizal and non-mycorrhizal seedlings.

Our results indicated that, compared with the nonmycorrhizal seedlings, both of the S1- and S3- mycorrhizal seedlings absorbed more $\mathrm{C}$ sources from the substrate. It has been confirmed experimentally that fungal symbiont can transfer $\mathrm{C}$ to the adult Goodyera repens (Cameron et al. 2006). That is, adult mycorrhizal orchids continue to receive $\mathrm{C}$ nutrition from their fungal partners, which is possibly because that the photosynthetic products cannot meet the demand of plant growth and development. Some researchers have found that mycorrhizal fungi could induce significant changes in the morphology of the host plant roots by increasing branches lengths and diameters (Hooker and Black 1995; Zhang et al. 2012). In another study, we also found that the host plant produced a larger number of root hairs (data unpublished). Such responses enable the plant to absorb more nutrients from the substrate. But it needs further investigation that the $\mathrm{C}$ enhancement from ${ }^{13} \mathrm{C}$-glucose in our orchid is due to direct absorption of host roots or transferring from intraradical fungal structure.

In addition, we found that the S1- and S3- mycorrhizal seedlings had significantly higher polysaccharides contents. It has been widely recognized that, during photosynthesis, atmospheric $\mathrm{CO}_{2}$ can be fixed to produce carbohydrates, especially polysaccharides. Our results demonstrated that the S3-mycorrhizal seedlings assimilated a larger amount $\mathrm{CO}_{2}$, indicating that more carbohydrates (including polysaccharides) were being accumulated. Moreover, soluble sugars within the substrate, e.g., sucrose and glucose, are effectively taken up after being transferred to the roots via the associated fungi (Pfeffer et al. 1999; Hynson et al. 2012). And soluble sugars are the common precursors of polysaccharides synthesis (Zha et al. 2007). Our results indicated that the mycorrhizal seedlings absorbed significantly more $\mathrm{C}$ from glucose than the non-mycorrhizal seedlings. Hence, we suggested that the increase of polysaccharides content in mycorrhizal plants may be related to the increase of $\mathrm{C}$ sources.

Plant polysaccharides are classified as either structural or non-structural (Potkins et al. 1991). The structural components of plant cells largely comprise carbohydrates, and are critical to cell wall functioning (Caffall and Mohnen 2009). Non-structural polysaccharides serve as an energy reserve for initial cell growth and expansion (Percival 1979). Thus, in our present study, the enhancement of biomass in the mycorrhizal seedlings was probably due to an increase in their non-stuctural polysaccharides accumulation.

\section{Conclusions}

In this study, two endophytic fungi (S1 and S3) sampled from wild $D$. officinale formed in vitro mycorrhizal associations with host roots, thereby markedly enhancing seedling growth. Both the S1- and S3- mycorrhizal seedlings received a larger amount of $\mathrm{C}$ source from substrates, while those seedlings exposed to the $\mathrm{S} 3$ fungus assimilated more $\mathrm{CO}_{2}$, which led to a higher percentage of polysaccharides. S1 and S3 differed in their extent of influence on the capacity of photosynthetic electron flow of $D$. officinale, indicating that they may have separate roles within the same host. Although we investigated carbon utilization of the green orchid in experimental conditions, further investigations should focus on the effects of symbiotic fungi on carbon nutrient acquisition of the adult $D$. officinale under field conditions. Moreover, the mechanism for increased photosynthesis capacity and polysaccharides accumulation via mycorrhizal associations should be explored in a more comprehensive way. 


\section{Abbreviations}

TAB: Cetyltrimethyl ammonium bromide; ITS: Internal transcribed region; mtLSU: Large subunit gene of mitochondrial rDNA; PBS: Phosphate buffer saline; PDA: Potato dextrose agar; PI: Propidium lodide; PPFD: Photosynthetic photon flux density; WGA-AF: Wheat germ agglutinin-alexa fluor; DPSII: Quantum yield of PSII.

\section{Competing interests}

The authors declare that they have no competing interests.

\section{Authors' contributions}

QXW carried out the whole experiment study and statistical analysis except the isolation of endophytic fungi. NY participated in the experimental design of ${ }^{13} \mathrm{C}$ stable isotope signature and helped to draft the manuscript. DGJ carried out the isolation of endophytic fungi. SYL participated in the collection of experimental materials. $\mathrm{HH}$ conceived of the study, and participated in its design and coordination and helped to draft the manuscript. All authors read and approved the final manuscript.

\section{Acknowledgements}

The authors are grateful to Dr. Jinsong Wu for his guidance in the visualization of mycorrhizal associations by laser scanning confocal microscopy; we also thank the Germplasm Bank of Wild Species, Southwest China, for providing that microscope. We also appreciate the relevant staff of Gaoligong Montain Nature Reserve, Yunnan Province. The research was supported by the Western Light Foundation of the Chinese Academy of Sciences and Small Population of Regression Project of the Forestry Department of Yunnan Province, China.

\section{Author details}

${ }^{1}$ Key Laboratory of Economic Plants and Biotechnology, Kunming Institute of Botany, Chinese Academy of Sciences, Kunming 650201, China. ${ }^{2}$ University of Chinese Academy of Sciences, Beijing 100049, China.

Received: 1 July 2013 Accepted: 26 August 2013

Published: 28 August 2013

\section{References}

Arditti J, Ghani AKA (2000) Numerical and physical properties of orchid seeds and their biological implications. New Phytol 145:367-421

Bruns TD, Szaro TM, Gardes M, Cullings KW, Pan JJ, Taylor DL, Horton TR, Kretzer A, Garbelotto M, Li Y (1998) A sequence database for the identification of ectomycorrhizal basidiomycetes by phylogenetic analysis. Mol Ecol 7:257-272

Caffall KH, Mohnen D (2009) The structure, function, and biosynthesis of plant cell wall pectic polysaccharides. Carbohydr Res 344:1879-1900

Cameron DD, Johnson I, Leake JR, Read DJ (2007) Mycorrhizal acquisition of inorganic phosphorus by the green-leaved terrestrial orchid Goodyera repens. Ann Bot 99:831-834

Cameron DD, Johnson I, Read DJ, Leake JR (2008) Giving and receiving: measuring the carbon cost of mycorrhizas in the green orchid, Goodyera repens. New Phytol 180:176-184

Cameron DD, Leake JR, Read DJ (2006) Mutualistic mycorrhiza in orchids: evidence from plant-fungus carbon and nitrogen transfers in the green-leaved terrestrial orchid Goodyera repens. New Phytol 171:405-416

Chang DCN, Chou LC (2007) Growth responses, enzyme activities, and component changes as influenced by Rhizoctonia orchid mycorrhiza on Anoectochilus formosanus Hayata. Bot Stud 48:445-451

Dearnaley JDW, Martos F, Selosse MA (2012) Fungal associations. In: Hock B (ed) Orchid mycorrhizas: molecular ecology, physiology, evolution and conservation aspects, 2nd edn. Springer, Verlag Berlin Heidelberg

Doehlemann G, Wahl R, Vranes M, De Vries RP, Kämper J, Kahmann R (2008) Establishment of compatibility in the Ustilago maydis/maize pathosystem. J Plant Physiol 165:29-40

Doyle JJ, Doyle JL (1987) A rapid DNA isolation procedure for small quantities of fresh leaf tissue. Phytochem Bull 19:11-15

Finlay RD (2004) Mycorrhizal fungi and their multifunctional roles. Mycologist 18:91-96
Genty B, Briantais JM, Baker NR (1989) The relationship between the quantum yield of photosynthetic electron transport and quenching of chlorophyll fluorescence. BBA-Gen Subjects 99:87-92

Harvais G (1982) An improved culture medium for growing the orchid Cypripedium reginae axenically. Can J Bot 60:2547-2555

Hou XQ, Guo SX (2009) Interaction between a dark septate endophytic isolate from Dendrobium sp. and roots of D. nobile seedlings. J Integr Plant Biol 51:374-381

Hooker JE, Black KE (1995) Arbuscular mycorrhizal fungi as components of sustainable soil-plants systems. Crit Rev Biotechnol 15:201-212

Hynson NA, Mambelli S, Amend AS, Dawson TE (2012) Measuring carbon gains from fungal networks in understory plants from the tribe Pyroleae (Ericaceae): a field manipulation and stable isotope approach. Oecologia 169:307-317

Johnson NC, Graham JH, Smith FA (1997) Functioning of mycorrhizal associations along the mutualism-parasitism continuum. New Phytol 135:575-585

Johnson TR, Stewart SL, Dutra D, Kane ME, Richardson L (2007) Asymbiotic and symbiotic seed germination of Eulophia alta (Orchidaceae)-preliminary evidence for the symbiotic culture advantage. Plant Cell Tiss Organ Cult 90:313-323

Liebel HT, Gebauer G (2011) Stable isotope signatures confirm carbon and nitrogen gain through ectomycorrhizas in the ghost orchid Epipogium aphyllum Swartz. Plant Biol 13:270-275

Lin Y, Li J, Li B, He T, Chun Z (2011) Effects of light quality on growth and development of protocorm-like bodies of Dendrobium officinale in vitro. Plant Cell Tiss Organ Cult 105:329-335

Luo HL, Cai TY, Cheng QL (2000) Enhancement of Dendrobium candidum polysaccharides on killing effect of LAK cells of umbilical cord and peripheral cancer patients in vitro. Chinese J Cancer Res 19:1124-1126

Ma M, Tan TK, Wong SM (2003) Identification and molecular phylogeny of Epulorhiza isolates from tropical orchids. Mycol Res 107:1041-1049

McCormick MK, Whigham DF, Sloan D, O'Malley K, Hodkinson B (2006) Orchidfungus fidelity: a marriage meant to last? Ecology 87:903-911

Mengel K, Kirkby EA (2001) Principles of plant nutrition. Kluwer Academic Publishers, The Netherlands

Mohanty P, Das MC, Kumaria S, Tandon P (2012) High-efficiency cryopreservation of the medicinal orchid Dendrobium nobile Lindl. Plant Cell Tiss Organ Cult 109:297-305

Murashige T, Skoog F (1962) Arevised medium for rapid growth and bioassays with tobacco tissue cultures. Physiol Plant 15:473-497

Percival E (1979) The polysaccharides of green, red and brown seaweeds: their basic structure, biosynthesis and function. Brit Phycol J 14:103-117

Pfeffer PE, Douds JDD, Bécard G, Shachar-Hill Y (1999) Carbon uptake and the metabolism and transport of lipids in an arbuscular mycorrhiza. Plant Physiol 120:587-598

Pharmacopoeia Committee of the P. R. China (2010) Pharmacopoeia of the People's Republic of China. People's Medical Publishing House, Beijing

Potkins ZV, Lawrence TLJ, Thomlinson JR (1991) Effects of structural and nonstructural polysaccharides in the diet of the growing pig on gastric emptying rate and rate of passage of digesta to the terminal ileum and through the total gastrointestinal tract. Brit J Nutr 65:391-413

Rasmussen HN, Rasmussen FN (2009) Orchid mycorrhiza: implications of a mycophagous life style. Oikos 118:334-345

Reid CPP, Kidd FA, Ekwebelam SA (1983) Nitrogen nutrition, photosynthesis and carbon allocation in ectomycorrizal pine. Plant Soil 71:415-432

Sheng M, Tang M, Chen H, Yang BW, Zhang FF, Huang YH (2008) Influence of arbuscular mycorrhizae on photosynthesis and water status of maize plants under salt stress. Mycorrhiza 18:287-296

Smith SE, Read DJ (1997) Mycorrhizal symbiosis. Academic Press, UK

Stewart SL, Kane ME (2007) Symbiotic seed germination and evidence for in vitro mycobiont specificity in Spiranthes brevilabris (Orchidaceae) and its implications for species-level conservation. In Vitro Cell Dev Biol Plant 43:178-186

Wang CY, Chiou CY, Wang HL, Krishnamurthy R, Venkatagiri S, Tan J, Yeh KW (2008) Carbohydrate mobilization and gene regulatory profile in the pseudobulb of Oncidium orchid during the flowering process. Planta 227:1063-1077

Zha XQ, Luo JP, Jiang ST, Wang JH (2007) Enhancement of polysaccharides production in suspension cultures of protocorm-like bodies from 
Dendrobium huoshanense by optimization of medium compositions and feeding of sucrose. Process Biochem 42:344-351

Zhang LC, Chen J, Lv YL, Gao C, Guo SX (2012) Mycena sp., a mycorrhizal fungus of the orchid Dendrobium officinale. Mycol Progress 11:395-401

Zhou YJ, Yang FS, Song XQ, Zhu GP, Hu MJ (2009) Effects of mycorrhizal fungi on seedling's growth and photosynthetic capability of Dendrobium sinense, endemic to Hainan. North Hortic 12:11-15

doi:10.1186/1999-3110-54-23

Cite this article as: Wang et al:: In vitro growth and carbon utilization of the green-leaved orchid Dendrobium officinale are promoted by mycorrhizal associations. Botanical Studies 2013 54:23.

\section{Submit your manuscript to a SpringerOpen ${ }^{\circ}$} journal and benefit from:

- Convenient online submission

- Rigorous peer review

- Immediate publication on acceptance

- Open access: articles freely available online

- High visibility within the field

- Retaining the copyright to your article

Submit your next manuscript at $\gg$ springeropen.com 